\title{
HORACIO, ARISTÓFANES Y EL ANSIA HUMANA DE VOLAR
}

\section{Elsa Margarita Bagnasco}

Resumen: En la oda 20 del libro segundo Horacio anuncia a Mecenas que él no morirá, sino que, poeta metamorfoseado en cisne, volará por los aires, contemplará en su vuelo gran parte de la tierra y será conocido por los pueblos del orbe.

El ansia de volar reconoce muchos antecedentes en la literatura griega, pero el trabajo se centra en su tratamiento en Las Aves de Aristófanes.

El análisis comparativo muestra que casi todos los aspectos señalados por Horacio se encuentran en la obra del comediógrafo griego, indiscutible antecedente del tema, y destaca lo peculiar del poeta romano.

En la oda 20 del libro segundo Horacio anuncia a Mecenas que él no morirá, sino que, poeta metamorfoseado en blanco cisne, volará por los aires; como ave cantora contemplará en su vuelo gran parte de la tierra y será conocido por los pueblos del orbe, ya sean bárbaros o romanizados.

La expresión del ansia de ser alado y de recorrer así los aires abandonando la tierra reconoce muchos antecedentes en la literatura griega, pero nos detendremos en Aristófanes, que se ocupó extensamente del asunto en su comedia Las Aves. Por cierto que las diferencias entre el poeta griego y el romano son muchas y grandes: distintos son los géneros literarios con que abordan el tema, distintas las motivaciones de los personajes, distintas las épocas, las lenguas, las culturas y las modalidades, distintos los destinatarios de los discursos poéticos. Sin embargo, son muchos los elementos en común, tanto en aspectos externos, como los detalles físicos de las metamorfosis, la antítesis aire-tierra, las referencias geográficas, o las menciones al canto de las aves y a la rapidez de su vuelo, como en aspectos más profundos tales como la presencia del hombre-pájaro, el cruce de realidad y fantasía y el anhelo de inmortalidad.

Acerquémonos al poema en cuestión, que es el que cierra el segundo libro de las odas horacianas.

Non usitata nec tenui ferar penna biformis per liquidum aethera vates...
Por inusitada y no débil ala seré

Ilevado, vate biforme, a través del limpido éter...

Horacio nos sumerge de entrata en la magnífica sensación del vuelo, realzada por la pureza del éter; sensación extraña para el hombre (non usitata penna), que también en eso requiere seguridad (nec tenui penna), aunque ésto último puede interpretarse además como una alusión a la fuerza de su obra poética, capaz de sostenerlo en su vuelo hacia la eternidad. En ese extraño viaje él será "biformis vates", es decir que, si bien transformado en ave, seguirá manteniendo su 
naturaleza humana y su condición de poeta; será un hombre-pájaro, un inspirado cantor.

Vayamos ahora a Aristófanes y recordemos algunos aspectos de su comedia Las Aves. La conversión del hombre en pájaro y su adaptación al modo de vida de las aves constituyen la base de la obra.Tereo, ya convertido en la Abubilla, mantiene sin embargo su naturaleza humana. Cuando el reyezuelo se presenta como pájaro esclavo Euélpides le pregunta asombrado si los pájaros necesitan servidores. La respuesta es "éste sl, creo que porque antes fue hombre", v. 75: oṽrós $\gamma^{\prime}$ ¿’ $\tau^{\prime}$

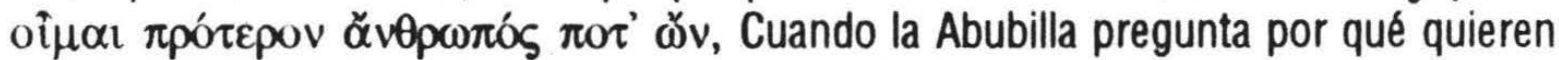
verlo, Euélpides le responde que desean consultarlo acerca de una ciudad adecuada porque él antes fue hombre como ellos y gustaba de no pagar las deudas como ellos y que luego, transformado en ave, habla sobrevolado la tierra y el mar, y afirma, usando el verbo en presente, "y tienes en tu espiritu todas las cosas cuantas tiene el

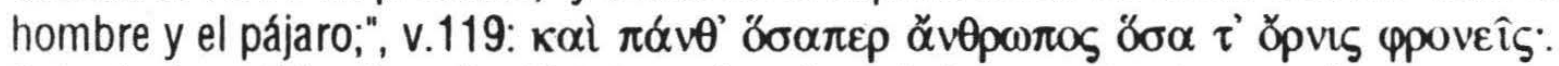
Ante la incertidumbre de Pistetero de cómo hacerse entender por las aves, la Abubilla le aclara que él, al permanecer largo tiempo con ellas les enseñó a hablar, facultad exclusiva del ser humano; que Tereo conserva después de su conversión, v.

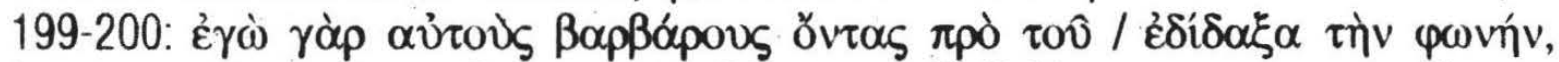

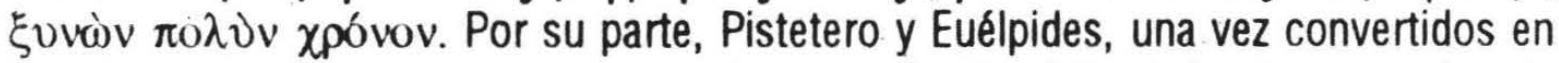
pájaros, siguen actuando como seres humanos hasta el fin de la obra; y varios de los personajes que visitan Nefelococigia pretenden hacer lo mismo, tales como el parricida (v. 1337 y sg.), el poeta ditirámbico (v. 1372 y sg.) y el sicofanta (v. 1410 y sg.).

Retomando el "vates" horaciano, tengamos presente que Cinesias, el poeta ditirámbico parodiado por Aristófanes, quiere alas precisamente para elevarse por los aires y tomar de las nubes nuevos preludios aéreos y nevados (v. 13821385), pues, según él, los más brillantes ditirambos son aéreos, sombríos, azulinos y alados (v. 1388-1390). Claro está que la intención satírica del comediógrafo al tratar el tema dista mucho de la nobleza del "vates" del poeta latino; pero tanto Horacio como Cinesias piensan en ser alados en favor de la continuidad de su labor poética.

Respecto de lo inusitado del plumaje en el ser humano, el "non usitata penna" horaciano encuentra su expresión burlesca en la comedia en los efectos de ridículo o de temor que los atributos propios de los seres alados, picos, crestas y plumas, provocan en los personajes; como en el encuentro de los protagonistas con el reyezuelo (V. 60-68, 85-91) y posteriormente con la Abubilla (v. 93-101), o las burlas que se hacen ambos entre sí al verse mutuamente convertidos en pájaros ( $v$. 801-806).

Retomemos la oda de Horacio. En los versos 3-5 nos dice:

.... Neque in terris morabor longius inuidiaque maior

urbis linquam.... y no moraré en la tierra por más tiempo y, más grande que la envidia, abandonaré las ciudades.

El poeta alude en estos versos al fin de su vida terrena y en ese "abandonar las ciudades" creemos notar la expresión de su deseo de distanciarse del 
contacto con los hombres, superando asi la evidia humana que parece incomodarlo bastante.

Examinemos ahora la posición de nuestros dos simpáticos atenienses, Euélpides y Pistetero. En primer lugar, lejos está de ellos el pensar en el fin de la vida terrena cuando inician su aventura, y su posterior decisión de abandonar la tierra para radicarse en la ciudad de las nubes, en medio de los seres alados, no tiene de ninguna manera el sentido que implica la enunciación horaciana. La primera intención de nuestros dos héroes es encontrar una ciudad libre de pleitos, pero terrena, donde poder vivir tranquilos. Así lo declara el mismo Euélpides en su discurso dirigido al público, en los versos 27 al 48, y posteriormente a la Abubilla cuando le expone el motivo de su visita (v. 112 y sg.). Aún después de la determinación de ambos de fundar Nefelococigia y de radicarse alli, no se advierte en ellos el deseo de alejarse del contacto humano, puesto que Pistetero se muestra dispuesto a recibir en la nueva ciudad a los hombres que, una vez alados, quieran incorporarse a ella (v. 1308-1312), considera positivo que llegue así a ser populosa (v. 1315), admite al parricida, aunque se cuida de aconsejarlo convenientemente (v. 1360-1369), y si echa en forma violenta a los demás postulantes es porque éstos pretendían convertir a Nefelococigia en la clase de ciudad que él había repudiado.

Pero, al margen de todas estas diferencias señaladas, encontramos en Horacio y en Aristófanes un esquema básico común:

1. el abandono de la vida en la tierra;

2. el abandono de la ciudad, de todas las ciudades en un caso, de Atenas en el otro;

3. la presencia de un elemento irritativo, la envidia en un caso, la "pleitomanía" en el otro.

La segunda estrofa de la oda horaciana que nos ocupa continúa así:

...Non ego pauperum

sanguis parentum, non ego quem uocas,

dilecte Maecenas, obibo nec

Stygia cohibebor unda.
Yo, sangre de padres pobres, al que

tú, querido Mecenas, convocas no

moriré ni seré retenido

por la onda estigia.

Horacio declara en forma rotunda su propia inmortalidad. La carrera de su existencia ha sido y será ascendente: de la humildad de su origen llega a la honrosa amistad con Mecenas y su destino final será burlar el poder de la Estigia. La triple negación con que descarta la posibilidad de su muerte no deja lugar a dudas en cuanto a la seguridad con que hace su afirmación. La muerte y el consiguiente dominio de la Estigia serán reemplazados por la conversión en ave, lo que implica su inmortalidad.

Este anhelo de inmortalidad, tan profundamente arraigado en la naturaleza humana, no aflora en absoluto ni en el espíritu de los dos intrépidos ancianos aventureros de Las Aves ni en el de los otros personajes de la comedia que aspiran a ser alados. La finalidad de todos ellos es totalmente práctica, vulgar, prosaica, sin atisbo alguno de transcendencia. Pero, en un momento de la comedia se establece esa extraña relación entre los pájaros y la inmortalidad. Al comenzar la parábasis el 
Coro de aves dice: "Ea, hombres que vivis oscuramente por naturaleza, semejantes al género de las hojas, débiles, figuras de arcilla, raza como sombras sin

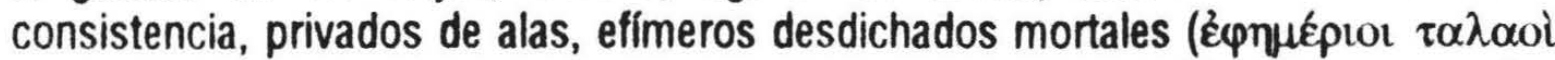
Bporoí), hombres similares a los sueños, prestadnos atención a nosotras, las

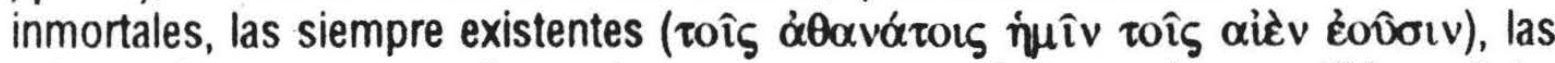
etéreas, las que no envejecen, las que se ocupan de cosas incorruptibles,..." (v. 685-689), y a continuación de este preámbulo desarrolan la famosa cosmogonía que establece que la raza de las aves es anterior a la de los dioses inmortales (v. 702-

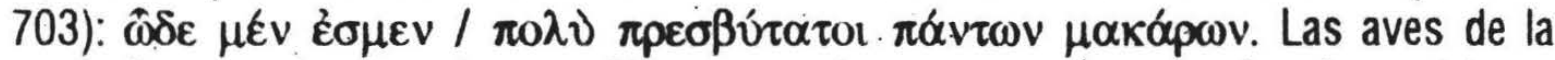
comedia, que aleccionadas por Pistetero, quieren ocupar para los hombres el lugar de dioses superiores a los bienaventurados olímpicos, se apresuran a señalar, en forma muy marcada, la diferencia esencial entre el ser humano y el ser divino, que consiste precisamente en la condición de mortal del primero frente a la inmortalidad y la ausencia de vejez del segundo, cualidades que, en consecuencia, ellas mismas deben atribuirse.

Por distintas motivaciones y con sentidos diferentes, tanto en el poeta latino como en el griego queda establecida la relación ave-eternidad.

En la tercera estrofa de su oda, Horacio nos hace asistir a su propia metamorfosis en pájaro:

lam, iam residunt cruribus asperae
pelles et album mutor in alitem
superne nascunturque leues
per digitos umerosque plumae.

La conversión se realiza ante nuestros ojos, merced a los procedimientos de actualización a los que el poeta recurre: los verbos en presente y la reiteración del "iam" al comienzo de la estrofa. Los elementos físicos que le dan su nueva caracterización son tres: la piel rugosa, las alas blancas y las leves plumas.

En el caso de nuestro comediógrafo, naturalmente las metamorfosis no podían producirse en escena. El autor se ve obligado, por razones técnicas, a recurrir a otros procedimientos. Asl, cuando Pistetero pregunta a la Abubilla cómo podrán seguirlo careciendo ellos de alas, ésta responde: "Nada temas, pues existe

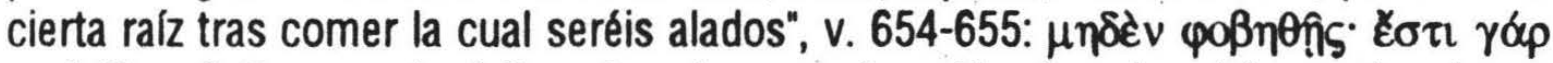

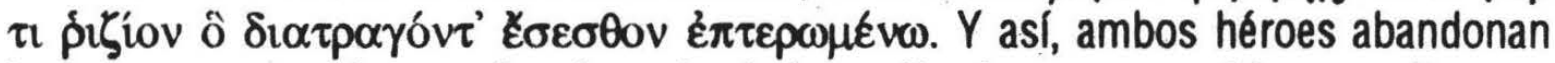
la escena, para volver a ella, después de la parábasis, ya convertidos en pájaros y burlándose uno del otro, en el episodio ya mencionado (v. 801-806). Otra manera de convertir a alguien en ave es entregarle simplemente las alas y demás accesorios. Así, el prudente Pistetero, enterado de la posible demanda al respecto, decide hacer rápida provisón de alas (v. 1309-1311), y cuando acepta emplumar al parricida le dice: "tomando esta ala y este espolón con la otra (mano), acostumbrándote a tener

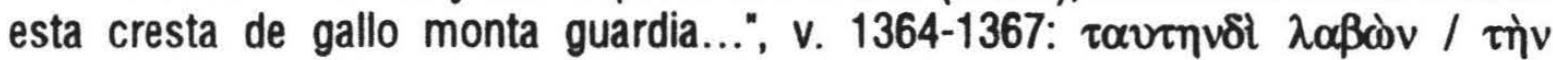

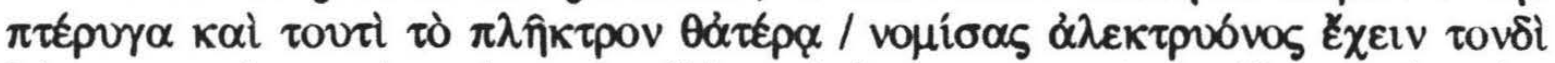

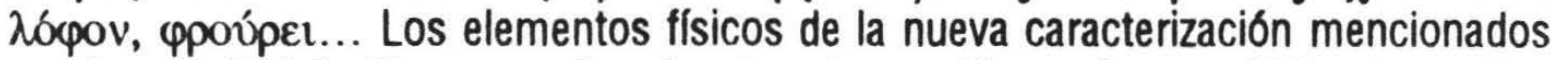

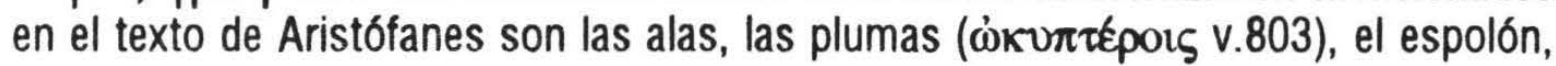


la cresta y los picos: $\chi \alpha ́ \alpha \mu \eta \mu \alpha$ (pico largo) v. 61; $\dot{\alpha}_{\alpha} \mu \varphi \propto s$ (pico ganchudo) v. 99; póryos (pico narigudo) v. 672.

Observamos que en lo referente a las metamorfosis en sí, aún con elementos comunes, los dos autores estudiados difieren bastante, a 10 cual contribuyen en gran parte los rasgos propios de la lírica y los de la comedia respectivamente.

Retomemos la oda horaciana. La cuarta y quinta estrofa dicen:

lam Daedalio ocior Icaro uisam gementis litora Bosphori Syrtisque Gaetulas canorus ales Hyperboreosque campos.

Me Colchus et qui dissimulat metum Marsae cohortis Dacus et ultimi noscent Geloni, me peritus discet Hiber Rhodanique potor.
Ya, más veloz que Icaro, hijo de Dédalo, visitaré, ave canora, las costas del resonante Bosforo y las Gétulas Sirtes y los campos Hiperbóreos. Me conocerán la Cólquide y el Dacio que disimula su temor a la cohorte Marsia y los Gelonios de los confines y me aprenderá el perito Ibero y el que bebe del Ródano.

Tras insistir con el procedimiento de actualización, el "iam" inicial, Horacio nos lleva en su vuelo por toda la tierra conocida, expresada a través de la mención de los cuatro puntos cardinales: en la cuarta estrofa vamos desde el norte (el Bósforo) hacia el sur (las Sirtes Gétulas, al norte de África) y nuevamente al norte, con los campos Hiperbóreos; en la quinta nos transladamos desde el oeste (la Cólquide, la Lacia y la Escitia) hacia el este (Iberia y la Galia). La intención del poeta de abarcar toda la tierra queda además subrayada por la mención de los confines, a través del adjetivo "ultimi" del verso 18, aplicado a los Gelonios, y la de los campos Hiperbóreos, que implica no sólo el territoreo real sino también el territorio mítico. El orgullo del ciudadano del imperio romano se le escapa a Horacio cuando nos recuerda el temor que experimentaban los dacios frente a la brava cohorte marsia, en un lugar en que la referencia no resulta nada adecuada y que más bien parece un recurso poco feliz para cumplir con las exigencias de la métrica. Desde otro punto de vista, aquil nos encontramos con el primer cruce de fantasía y realidad dentro de esta oda, cruce que va a repetirse en el brusco cambio de tono de la última estrofa. El orgullo del poeta se revela en los verbos "noscent" (v. 19) y "discent" (v. 20), y en la repetición del "me" (v. 17 y 19), que constituyen el profético presagio de la difusión que alcanzará su obra, no sólo entre los pueblos ya romanizados (a eso alude el "peritus" del verso 19), sino también entre todos los de la tierra. Notemos que en la cuarta estrofa Horacio no va a ser visto, será él quien contemplará la tierra desde su vuelo. Giorgio Pasquali, en su libro Oracio Lirico (pág. 552), señala que también los griegos de la antigüedad experimentaban ese sentimiento, mezcla de desdén por la vida terrena y el deseo de contemplar las cosas desde lo alto, y cita al respecto los versos 278-284 de Las Nubes de Aristófanes en los que el Coro de nubes dice que se levantarán desde el océano "...hacia las cumbres de arbolada cabellera de las altas montañas, desde donde contemplamos de lejos las cimas que aparecen a la distancia, y la sagrada tierra lozana en frutos y las resonancias de los

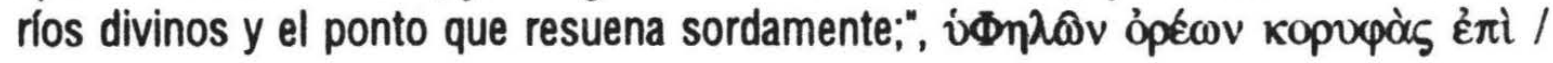




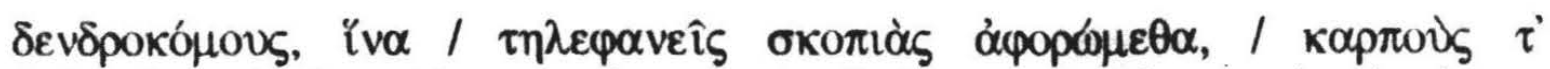

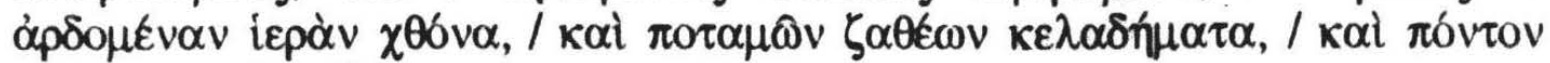

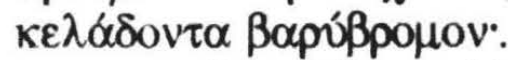

Pasquali considera que un sentimiento similar anima a Horacio en la estrofa de los versos 13 a 18 de la oda que nos ocupa.

En este mismo pasaje nuestro poeta señala dos rasgos del ser alado en que se convertirá: la rapidez de su vuelo (ocior Icaro) y su condición de cantor (canorus).

Retornemos a la comedia del ateniense y examinemos si se dan en ella, y cómo se dan los elementos analizados en las estrofas horacianas. En la respuesta que da Euélpides a la Abubilla cuando ésta lo interroga acerca del por qué de su venida, en un momento dice: "luego, por otra parte, habiéntode cambiado hacia la naturaleza de los pájaros, sobrevolabas en círculo tanto la tierra como el mar," v.

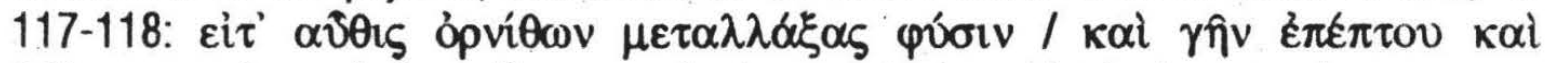

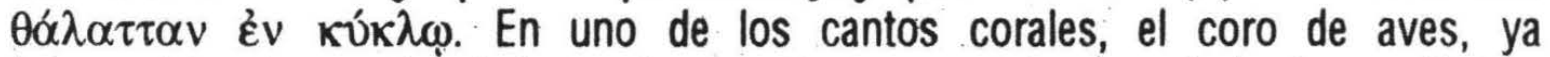
convencidas de su divindad, dice que todos los mortales les ofrecerán sacrificios, "pues veo toda la tierra y salvo los abundantes frutos", v. 1081-1082: $\pi \hat{\alpha} \sigma \alpha \nu \mu \dot{\varepsilon} v$

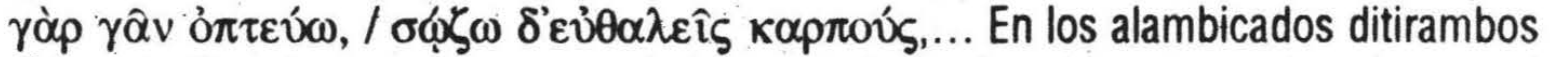
del poeta Cinesias encontramos prácticamente todos los elementos trabajados por el poeta latino. Vale la pena revisarlos, aunque sea parcialmente: "Vuelo hacia el Olimpo con ligeras alas y vuelo de un camino al otro de los ritmos"..." Imagen de volátiles que corren por los aires, aves de largo cuello,"..." lanzándome a una carrera sobre el mar ojalá yo vaya junto con los soplos de los vientos."..." Avanzando ya hacia el camino del sur, ya al contrario acercando mi cuerpo al Bóreas cortando el surco sin puerto del éter."

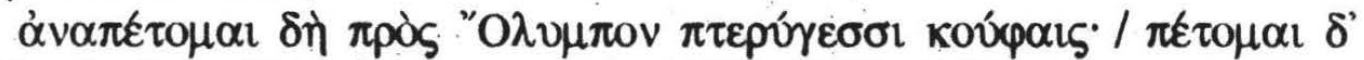

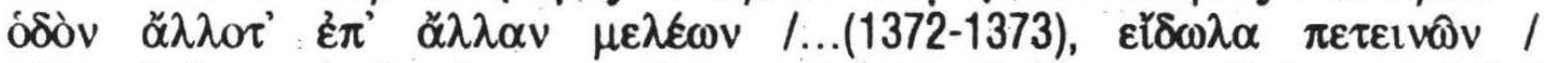

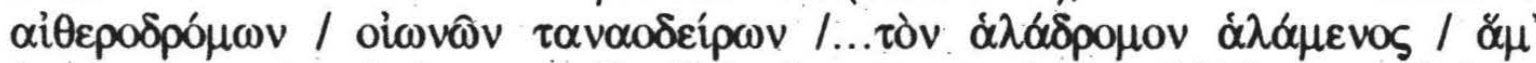

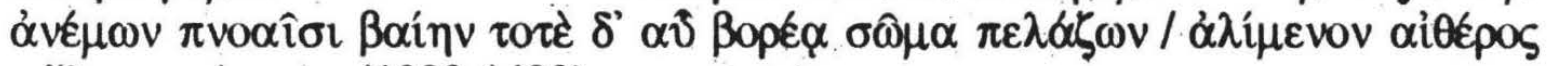
$\alpha \tilde{\lambda} \alpha \chi \alpha \tau \varepsilon \mu v \omega v$. (1393-1400)

El texto está interrumpido por omisiones o por el diálogo.

Es fácil advertir la coincidencia de los aspectos señalados por ambos poetas: la mención de los puntos cardinales para expresar la totalidad de la tierra, la ligereza del traslado por el éter, y la presencia del canto, esta última subrayada por el mismo Cinesias cuando dice en el verso 1380: "Quiero llegar a ser ave, ruiseñor

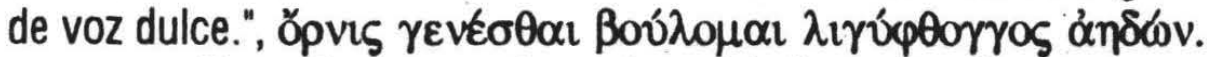

Naturalmente, referencias al bello canto de las aves se encuentran en otros pasajes de la comedia. Cuando la Abubilla llama a su esposa, convertida en ruiseñor, elogia la belleza de su triste canto que asciende hasta los olimpicos y recibe la respuesta de Febo y del coro de los bienaventurados (v. 209-222). Terminado el llamado de la Abubilla, Pistetero exclama: "Oh, Zeus soberano, qué voz

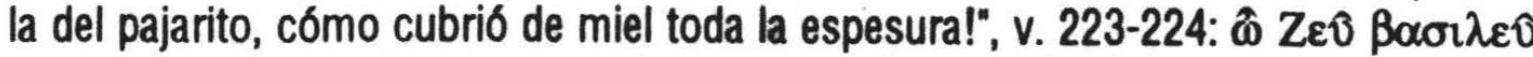

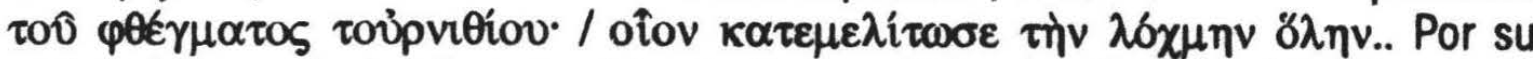

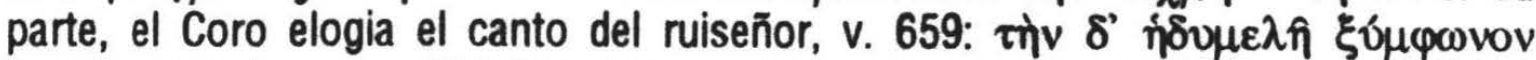

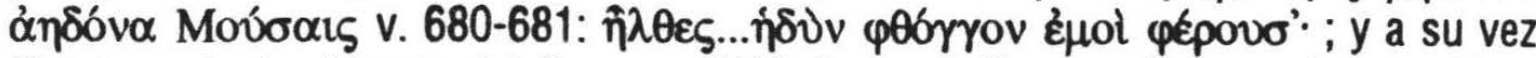

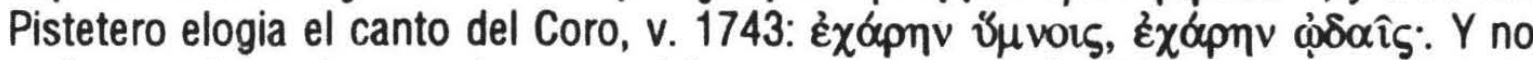
podemos dejar de mencionar aquil las preciosas estrofa (737-751) y antiestrofa (769-784) de la parábasis, en las que los cantos de las aves en general y el de los 
cisnes en particular, expresiones de verdadera poesía, se vinculan con las Musas, con Apolo y con otros inmortales; pasajes en los que Aristófanes aprovecha para desplegar sus grandes faculdades de poeta lírico. Lo mismo que en Horacio, encontramos en Aristófanes establecida la relación canto de las aves-poesía.

Son muchas las referencias a la velocidad del vuelo de las aves en la comedia: el servidor de la Abubilla debe correr, lo que da lugar al juego de palabras

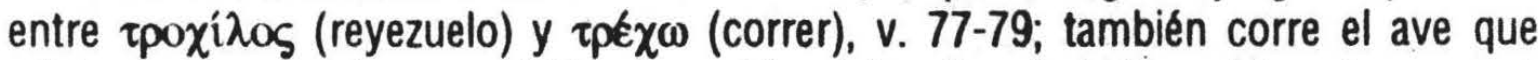
oficia como mensajero, v. 1121; y la rapidez del vuelo y la belleza del canto se unen en el verso 233, que se refiere a la raza de las aves: "que vuela rápidamente y lanza

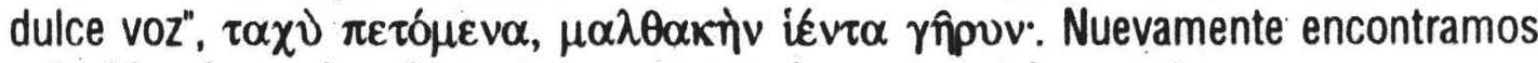
coincidencias en los elementos puestos en juego por ambos poetas.

Volvamos a Horacio y consideremos la última estrofa de su oda:

Absint inani funere neniae

luctusque turpes et querimoniae; conpesce clamorem ac sepulcri mitte superuacuos honores.
Estén ausentes de mi inútil funeral las nenias, y los desagradables lutos y los lamentos; reprime el clamor y omite los superfluos honores del sepulcro.

Indiscutiblemente el cambio de tono es brusco. De golpe nos aparta de esa blanca ave en que se ha convertido y nos coloca en el campo de las ceremonias fúnebres. Clara está la relación temática con el resto de la oda, precisamente por la metamorfosis que implica su inmortalidad hay un rechazo por el funeral que resulta "inani" (inútil) y por los honores tributados al sepulcro que son "superuacuos" (superfluos). De todas maneras nos ha hecho dar un salto desde la fantasía hacia la realidad, y aquí encontramos la aplicación práctica y la norma de conducta que se desprenden del poema y a las que todo él parece apuntar.

El cruce de fantasía y realidad es un ingrediente inseparable de la comedia antigua y una constante en toda la obra de Aristófanes. No podía pues faltar en Las Aves, en la que encontramos numerosos ejemplos; sólo que en el risueño espíritu de la comedia la aplicación práctica del hecho de convertirse en ser alado nada tiene que ver con la muerte sino que se orienta hacia la vida en sus aspectos más cotidianos. En el antepírrema de la parábasis (785-800), el Coro de aves intenta convencer al público de que nada es mejor que tener alas y lo demuestra señalando algunas aplicaciones prácticas de las mismas: si un espectador, importunado por una tragedia, sintiera hambre podría, en un vuelo, ir a su casa, comer y volver al teatro; lo mismo podría hacer quien se sintiera apremiado por otra necesidad física, sin necesidad de ensuciar su manto; y si un enamorado viera al marido de su dama entre los espectadores, podrla volar hacia ella, disfrutarla y regresar rápidamente al teatro. Ya hemos visto que Cinesias quiere ser alado para poder recoger de las nubes nuevos ritmos poéticos (v. 1382 y sg.); y el sicofanta necesita desesperadamente las alas para cumplir mejor su "oficio": recorrer las ciudades de las islas, citar a juicio, volver a buscar los bienes del condenado sin darle tiempo a nada y todo con la velocidad de un trompo y a resguardo del ataque de los ladrones (v. 1410 y sg.). Como vemos, Aristofanes nos instala en una realidad cotidiana y nos lleva hasta sus aspectos más prosaicos y vulgares.

El análisis efectuado pretendió demostrar que, pese a las grandes diferencias oportunamente anotadas, son muchos los elementos en común 
elaborados por ambos autores en el tratamiento del asunto. Casi todos los aspectos señalados por Horacio se encuentran, de un modo u otro, expresados en la obra de Aristófanes, que resulta asl un indiscutible antecedente del tema. Por alejados que parezean entre sí, ambos tienen un hilo conductor común: el ansia humana de volar para evadirse de una incómoda realidad; sólo que el poeta romano da un paso más adelante, pues aspira, a través de ese vuelo, llegar a la eternidad, anhelo del que no hay ni un atisbo en la obra del poeta griego.

Pero en la oda de Horacio resuena una nota dominante, del todo ausente de nuestra comedia: el orgullo; orgullo de su faculdad de poeta, orgullo de su superioridad, orgullo de su obra, orgullo de su vida, orgullo de su condición de romano y orgullo de su innegable peremnidad que lo lleva a despreciar algo tan importante para el hombre antiguo como son las honras funerarias. Orgullo que el transcurso de los siglos ha demostrado que era totalmente legítimo en el inmortal poeta romano.

Bibliografia

HORACE. Odes et Epodes, París, Les Belles Lettres, 1981.

ARISTOPHANIS. Comoediae, Oxford, The University Press, 1964.

PASQUALI, G. Orazio Lirico, Firenze, Le Monnier, 1986. 